\title{
Adsorption and desorption characteristics of fluoride in the calcareous and siliceous sand sheet aquifers of south-west Victoria, Australia
}

\author{
S. A. Salzman ${ }^{1}$, G. Allinson ${ }^{2}$, F. Stagnitti ${ }^{1}$ R. J. Hill ${ }^{3}$, \\ L. Thwaites ${ }^{4}$, D. Ierodiaconou ${ }^{1}$, R. Carr ${ }^{1}$, J. Sherwood $^{1}$ \\ \& V. Versace ${ }^{1}$ \\ ${ }^{I}$ Deakin University, Australia \\ ${ }^{2}$ Department of Primary Industries, Australia \\ ${ }^{3}$ Ecoplan Pty Ltd, Australia \\ ${ }^{4}$ South Australian Research and Development Institute, Australia
}

\begin{abstract}
This study assessed the sustainability of utilising groundwater systems to manage an aluminium smelter's fluoridated trade wastewater stream. Replacing ocean discharge of the wastewater with land irrigation is one option. Using a groundwater model (developed using MODFLOW incorporating parameter estimation software (PEST-ASP)), we found that most of the groundwater flow takes place through surface sands. Fluoride is adsorbed in these sands during the drier summer months, but desorption is rapid when winter rain flushes the aquifer. Underlying clays and other layers prevent significant contamination of the deeper aquifer.
\end{abstract}

Keywords: groundwater flow, fluoridated trade wastewater, adsorbed, desorption.

\section{Introduction}

Fluoride is considered to be the third most important air pollutant after sulphur dioxide and ozone because it is highly toxic to some plant species [1]. Most fluoride in or on terrestrial plants results from aerial fluoride, but small amounts will be taken up from irrigation water [2], and soluble fluoride salts can be taken 


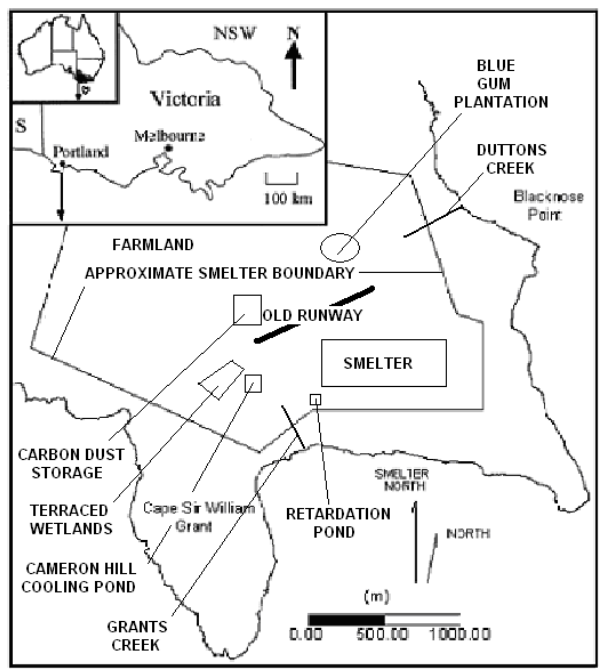

Figure 1: Location of Portland, Victoria, Australia, and an overview of the smelter site.

up by the leaves from spray irrigation [3-6]. Aluminium smelters have been identified as significant producers of fluoride-rich fumes [7-10]; Portland Aluminium, the smelter studied in this paper, is no exception.

Portland is a small rural coastal township in the south west of Victoria, Australia, and is proximal host to a large aluminium smelter (Portland Aluminium), fig. 1. Volatile gases, including fluorine containing compounds, produced from the smelting process are collected, by gas collecting hoods and manifolds, and processed in centralised gas treatment and recovery facilities. Although these recovery facilities are an essential part of an environmentally sustainable practice, they are not $100 \%$ efficient, and some 120 tonnes per annum fluorides are emitted as an airborne contaminant.

On the smelter site there are a variety of habitats that could be affected by the fluoride emitted by the smelter. For instance, there are man-made $(\sim 20)$ and natural wetlands ( 30), two creeks (Grants and Duttons), and a groundwater system with a phreatic surface, very close to the land surface. Eleven natural plant community types have been described [11], which prior to smelter construction ranged from wholly natural, to pasture or disturbed areas of mainly exotic composition, but overall contained some 522 species, 386 of which are native to Victoria, and some of which are exceedingly rare, including Mellblom's spider orchid (Caladenia hastate), which is endemic to a small, localised area near the smelter itself. The two creeks are home to two species of native fish, including the rare and endangered Mountain Galaxid (Galaxias olidus) in Dutton's Creek.

Portland Aluminium's trade wastewater contains $\sim 12 \mathrm{mg} / \mathrm{L} \mathrm{F}^{-}$(once it is combined with the storm water collected on-site), and various strategies are being considered to meet a 'zero off-site' discharge policy to commence in 2010 , 
including land irrigation of the wastewater. Soils exposed to fluoride are reported to act as sinks, purportedly accumulating fluoride in both wet and dry depositional conditions [12]. Consequently, the aims of this study were to assess fluoride adsorption and desorption in the site's geological media, and investigate the possible impacts of various irrigation and groundwater discharge regimes on aquatic resources, to determine the best way to meet the 'zero off-site' mandate from management. A number of on-site re-use scenarios are modelled and considered.

\section{Materials and methods}

\subsection{Geological data}

Sequentially, the geological profile of the area comprises an uppermost blanket of siliceous and calcareous sands, with some reddish clay now exposed in the farmland area, basaltic layers, the thin impervious Whalers Bluff Formation, the Port Campbell Limestone Formation, a 600m thick layer of impervious marl, and the underlying Dilwyn Aquifer. Many formations in the stratigraphic sequence are aquifers, while others act as aquicludes or confining layers. The thickness of the basalt layer immediately below the surface sands varies from about 30 to $45 \mathrm{~m}$, compared to approximately $10 \mathrm{~m}$, closer to the Portland township to the north west of the smelter [13]. Evidence suggests that the Whalers Bluff Formation, and the overlying basalt and basalt derived clay strata, are protective barriers to the deeper aquifers. This is important since the aquifers are used for a variety of anthropogenic purposes. In particular, the Dilwyn Aquifer provides Portland's potable water supply.

Prior to the smelter's construction in the early 1980s, approximately 200 probe holes were sunk to assess the site's suitability, including both standard penetration tests and groundwater monitoring bores. Other investigations commissioned by Portland Aluminium since the building of the smelter have also required the identification of spatially referenced geological data. These historical records, including 35 bores and piezometers installed for this study, were used to summarise the geological stratigraphic features found on the Portland site.

\subsection{Topographic data}

From the smelter site and the surrounding countryside approximately 12,000 Cartesian coordinates were recorded using a global positioning system, and stored in an AutoCAD file. This data was extracted and converted to a Microsoft ${ }^{\mathrm{TM}}$ Excel file and loaded into Esri ARCView ${ }^{\circledR}$ for spatial interpretation. ARCview was then used to interpolate the file within predefined boundaries. The ARCview basin application software script was then used to define areas within the domain where water would pool based on estimated runoff. 


\subsection{Collection and preparation of soil samples}

All laboratory glass and plastic-ware used during the processing and preparation of samples were washed in Extran and then soaked in a $10 \% \mathrm{HNO}_{3}$ (UNIVAR $99 \%$ purity) solution for 24 hours prior to use. Deionised water with a resistivity of at least $18 \mathrm{M} \Omega / \mathrm{cm}$ was prepared by passing singly distilled water through a Milli-Q water Purification System. Fluoride (as NaF, ANALR 99\% purity) was obtained from the manufacturer BDH.

On the 11 March 2001, seventy-seven soil samples were collected from locations surrounding the smelter, to a maximum distance of approximately $2 \mathrm{~km}$ from the smelter's hard-pan area. Sample locations were selected prior to sampling so that as much of the site as possible could be spatially represented. Soils were then collected from easily accessible bare patches of ground as close as possible to the designated sample site, within which samples were collected randomly. The top $3 \mathrm{~cm}$ of soil was scooped into a sterile $60 \mathrm{~mL}$ sealable specimen jar (Sterile Label, Yellow Capped, Gamma Sterile, Safety Plus Pty Ltd, Melbourne Australia). The sample jars were sealed, and immediately returned to the laboratory, where they were sieved to a grain size of no more than $1 \mathrm{~mm}$ (Laboratory Test Sieve, Endecotts Ltd, London England). Approximately $25 \mathrm{~g}$ of each sample was then placed into a clean $130 \mathrm{~mL}$ polyethylene container (Safety Plus Pty Ltd, Melbourne Australia). To each container $100 \mathrm{~mL}$ of deionised water was added. Containers were then shaken end over end at approximately 30 revolutions per minute for 72 hours. After this time, the samples were centrifuged at $1000 \mathrm{rpm}$ for 1 hour (Thomas Optical Scientific Co. Pty Ltd). The supernatant was then removed and filtered through a $45 \mu \mathrm{m}$ membrane into acid washed (10\% HNO3) $250 \mathrm{ml}$ poly-ethylene containers (Safety Plus Pty Ltd, Melbourne Australia) prior to analysis.

\subsection{Collection and preparation of groundwater}

Twelve groundwater monitoring bores were installed in the early 1980s at locations where the smelter has been licensed to store spent pot linings. All bores are within $1 \mathrm{~km}$ of the smelter's vents. The concentration of fluoride in the groundwater has been monitored via these bores since that time, and data on the fluoride concentration in these bores was supplied by Portland Aluminium for the period February 1996 to July 2000.

A further 25 bores and 10 piezometers were installed by the project team during this study to monitor the fluoride in the surficial aquifer. These monitoring sites were permeated spatially throughout the model domain. Using data from the pre-existing bores it was estimated that the average ground water phreatic flux was $1.5 \mathrm{~m} /$ year, with the nadir in the summer months (Dec-March), and the zenith in the wetter winter months (Jun-August). Groundwater height below ground data was obtained from smelter records for the period February 1996 to July 2000. Arithmetic mean averages were used to estimate annual phreatic flux. Bores were therefore installed during the drier summer period, and, when contact was made with the phreatic surface, the holes were augured as much as 2 meters deeper (to an average depth of around 3.5 to $4.5 \mathrm{~m}$ ). 
Groundwater samples were collected on the 23/08/2001, 04/10/2001, $04 / 12 / 2001,04 / 02 / 2002,10 / 04 / 2002$, and 03/06/2002. Sampling of the bores was conducted by lowering a small submersible pump down the centre of each well. The bores were purged by pumping four times the estimated volume of the well at that time. This water was collected in $20 \mathrm{~L}$ plastic buckets that were not emptied until the sample had been extracted from the bore because in the highly hydraulically conductive environment found on the Portland site (mean horizontal groundwater flow $15 \pm 14 \mathrm{~m} /$ day [14], with the phreatic surface so close to the land surface (within 1-2 m), and with sandy porous soils, it is possible that water pumped directly onto the ground surface could have soaked straight back into the ground water table prior to purge completion, thus compromising sample integrity. After purging a bore a groundwater sample was collected in $250 \mathrm{ml}$ poly-ethylene containers. All sample bottles were rinsed three times with sample prior to collection, after which samples were placed in ice for transportation. If analysis was unable to be conducted immediately, samples were frozen. All aqueous samples were filtered through a $45 \mu \mathrm{m}$ filter (Whatmans Ltd England) and all analysis was conducted within 5 days.

\subsection{Fluoride adsorption on geological media}

As described above, geomorphologically, the surficial aquifer underlying the Portland Smelter has two main features, namely surficial sands (both calcareous and siliceous) overlying basalt derived clays. However, there exists considerable heterogeneity within the confines of each stratigraphical element. Therefore, the adsorptive potential was investigated to assess for adsorptive differences within the same stratigraphic feature. Both Langmuir and Freundlich adsorption isotherm models were used to determine the potential for fluoride to adsorb to aquifer material. Specifically, the Langmuir adsorption isotherm was used to assess the adsorptive capabilities of aquifer mediums, whilst the Freundlich adsorption isotherm model, being a summation of a distribution of Langmuir equations [15], was also applied to the data.

Following a range-finding test (method and data not presented), the fluoride adsorptive potential of aquifer mediums was determined using soils extracted when the 25 new bores were installed for this study. Soils were air-dried, then gently homogenised and desiccated in aluminium trays for $72 \mathrm{~h}$ at room temperature $\left(\sim 25^{\circ} \mathrm{C}\right)$. Approximately $5 \mathrm{~g}$ of soil was then weighed into a $60 \mathrm{~mL}$ polyethylene container. $50 \mathrm{~mL}$ of standard fluoride solution (as NaF, ANALR 99\% Purity, BDH Chemicals) was then added to the soil. Fluoride test solutions were $0,5,10,20,50,250,500$ and $1000 \mathrm{mg} / \mathrm{L} \mathrm{F}^{-}$. All experiments were conducted in triplicate at a room temperature of $21^{\circ} \mathrm{C}$. The samples were then simultaneously agitated for $72 \mathrm{~h}$. After agitation, the samples were centrifuged at 1000rpm for $1 \mathrm{~h}$ (Thomas Optical Scientific Co. Pty Ltd). The supernatant liquid was removed and passed through a $45 \mu \mathrm{m}$ sieve (Whatmans Ltd England). Determination of fluoride concentration was conducted immediately thereafter. 


\subsection{Fluoride retention in the surficial sandy aquifer}

There was little evidence of any historic increase in bore water fluoride concentrations on the Portland Aluminium smelter site. Consequently, to test the hypothesis that fluoride is removed from the system by either flushing resulting from rainfall, or complexation, a simple leaching experiment was undertaken using re-packed soil columns. Four $45 \mu \mathrm{m}$ filters (Whatmans Ltd England), one on top of the other, were taped to the base of a $40 \mathrm{~cm}$ length of acid washed, 150 $\mathrm{mm}$ diameter PVC pipes, in place so that a solution could only exit the chamber through the filter paper. To ensure the filter paper retained its integrity throughout the experiment, a $152 \mathrm{~mm}$ diameter, acid washed polyethylene gauze was taped below the filter paper. A polyethylene funnel $(120 \mathrm{~mm})$ was then positioned at the base of the PVC unit, and taped in place. The unit was then placed on a Bunsen burner tripod, and a $600 \mathrm{~mL}$ beaker positioned below the funnel for solution collection. Three such units were constructed, such that the experiment could be conducted in triplicate.

To each of the three experimental units, a $1000 \mathrm{~mL}$ volume of homogenised soil sample was added. The soil was not compressed into the unit. Settlement of the soil was achieved by gently agitating each PVC unit. Compaction of the soil would have been inappropriate, as it would change the medium's fluidity (the base of most bores drilled for this study collapsed when the auger bit penetrated below the phreatic surface). The base of each experimental unit was sealed by placing a rubber stopper into the funnel outlet. Thereafter, $1000 \mathrm{~mL}$ of $10 \mathrm{mg} / \mathrm{L}$ $\mathrm{F}^{-}$solution was added. The experimental units were then left to equilibrate for 72 $\mathrm{h}$, after which the solution was drained and the fluoride concentration analysed. Each chamber was then flushed continually with deionised water. A constant head of deionised water was maintained in each experimental unit by using an automated siphon. The volume of deionised water that flowed through each unit was measured as it was collected and subsequently analysed for fluoride concentration. The experiment was conducted until the concentration of fluoride was below detectable limits $(0.02 \mathrm{mg} / \mathrm{L})$ in leachate from each of the three experimental units. The concentration of fluoride was then plotted against the total volume of water flushed (L) for the experiment duration (hours).

\subsection{Fluoride analysis}

Fluoride concentrations were determined using an ion selective electrode (Denver Instrument, model 25, pH/ion meter) with a TISAB buffer (Method APHA $4500-\mathrm{F}-\mathrm{C}$ ). $10 \mathrm{~mL}$ samples and $10 \mathrm{~mL}$ of the buffering reagent were continually stirred whilst monitoring with the ion selective electrode. A measurement was taken when drift had stabilised, usually after approximately $4 \frac{1}{2}$ minutes. The electrode was calibrated with known standards and drift was checked every ten samples. Fluoride data was then interpolated using the kriging linear variogram model in the SURFER ${ }^{6.0}$ software package (Golden Software Inc, 1997). 


\section{Results and discussion}

\subsection{Fluoride contamination}

Higher fluoride concentrations are found in the soils around the smelter site than at the site boundary, fig. 2, with two hot spots to the west of the smelter itself. This is consistent with [10], who reported that fluoride concentrations associated with damage to three broad leaved species of plants was limited to within $2 \mathrm{~km}$ of a smelter in Norway. The source of the contamination is likely to be from airborne fluoride emitted from the smelter's stack.

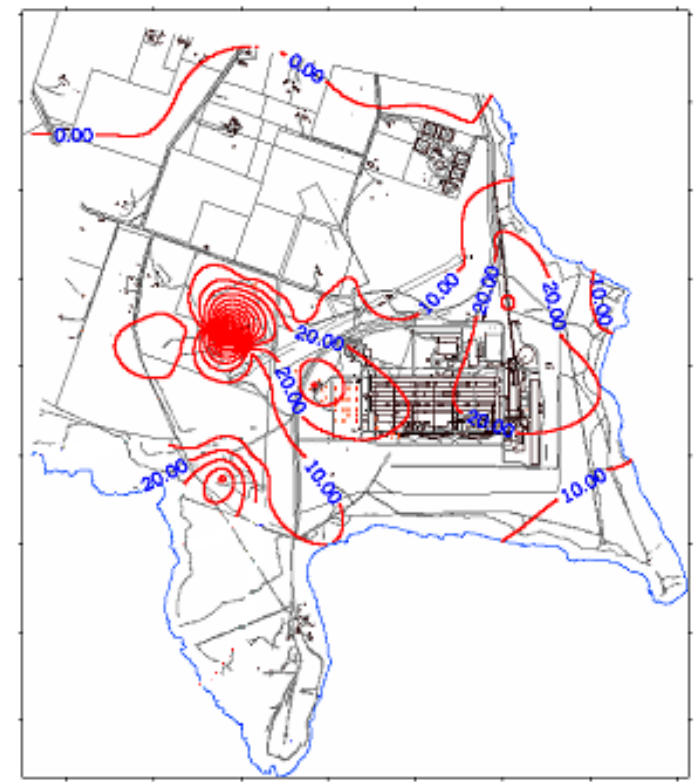

Figure 2: Fluoride concentration $(\mathrm{mg} / \mathrm{kg})$ in the surface soils of the smelter site on 11 March 2001.

One of the hot spots is the carbon dust storage area, an area used to store spent pot linings, where fluoride concentrations as high as $130 \mathrm{mg} / \mathrm{kg}$ were observed in the surface soils. Some four hundred metres to the south there is another hot spot, which smelter management has indicated is where the spent pot linings were once stored, fig. 2.

Topographic analysis with ARCview showed that there were seventeen micro-catchments contained within the site's major catchment, fig. 3. Two of these encompass the outflows of the two small creeks that originate on the site (Grants Creek and Dutton's Creek). Most of the potentially vulnerable wetlands on the site are located in the west of the catchment. The two creeks drain most of these catchments. The diversity of fresh water habitats that dot the site, have historically remained largely uncontaminated, with the concentration of fluoride 
well below $1 \mathrm{mg} / \mathrm{L}$. However, the smelter uses specific ponds to manage treated process water, which is combined with storm water and pumped to specific locations. These areas consistently show elevated levels of fluoride of between 5 and $15 \mathrm{mg} / \mathrm{L}$. [16]. Some of these ponds have been shown to be leaky [16], 2001), providing a fluoride source to the surficial aquifer. Spent pot linings are also stored on-site until they can be transported off-site for recycling. The concentration of leached fluoride contained in runoff waters from their storage area has been as high as $50 \mathrm{mg} / \mathrm{L}$. Although this runoff drains to a clay-lined pond, where the peripheral clay bund purportedly conjoins the clay strata below, in recent years this pond has also shown to be leaking.

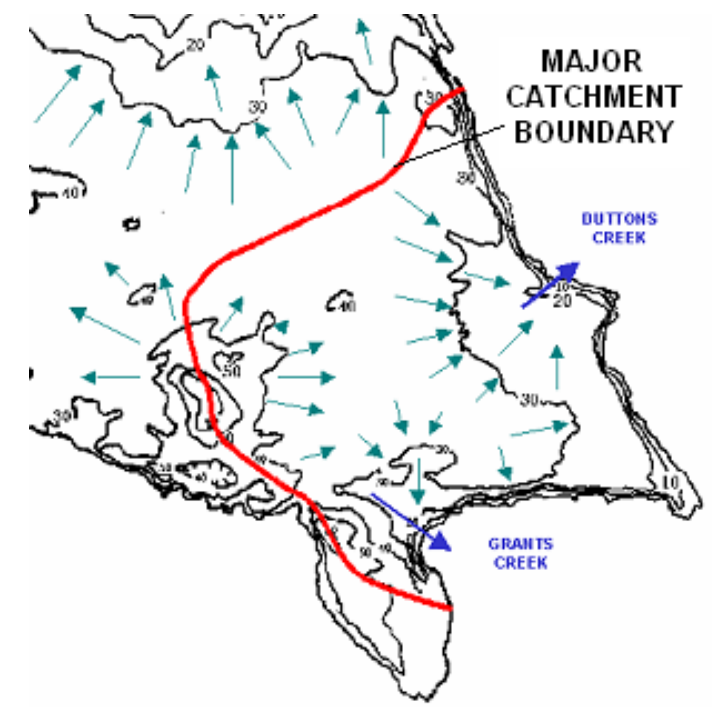

Figure 3: $\quad$ Macro catchment definition of the smelter site.

Naturally occurring fluoride can be found in the groundwater surrounding the smelter site at 0.1 to $0.3 \mathrm{mg} / \mathrm{L}$ in groundwater [17]. Similar background fluoride concentrations (i.e. 0.1 to $0.3 \mathrm{mg} / \mathrm{L}$ ) are found in all bar two of the old (pre2000) monitoring bores, and, even where fluoride concentrations are elevated, the average concentration has not increased over the years, but has remained at between 1.5 and $2.0 \mathrm{mg} / \mathrm{L}$. In other words, fluoride has not been accumulating in the groundwater.

Further investigation of the historical data provided for the older groundwater monitoring bore logs shows considerable variation in the concentration of fluoride over time. This can be seen in the hydrographs from these bores, e.g. as shown in fig 4. The most likely explanation for this is that fluoride concentration in the groundwater is associated with rainfall events. Rainfall absorbs airborne fluoride, falls to the ground and quickly enters the surficial aquifer. The concentration of fluoride in the groundwater will therefore depend on where on the site precipitation takes place, the rate of precipitation, on the rate of 
adsorption/desorportion by the soil and on the rate at which groundwater is removed from the site via the creeks or other means.

There is evidence of fluoride groundwater contamination in two of the smelters old monitoring bores. Both are associated with the Carbon Dust Storage Area, where the clay pond lining of the wetland adjacent to the storage area is leaking. There are also other hot spots of elevated fluoride in the groundwater, fig. 2. One is immediately adjacent to the west of the smelter, and results from storage of spent pot linings at this location. Finally, there is another source of fluoride to the north of the site, as highlighted by the contour maps in fig 5 .

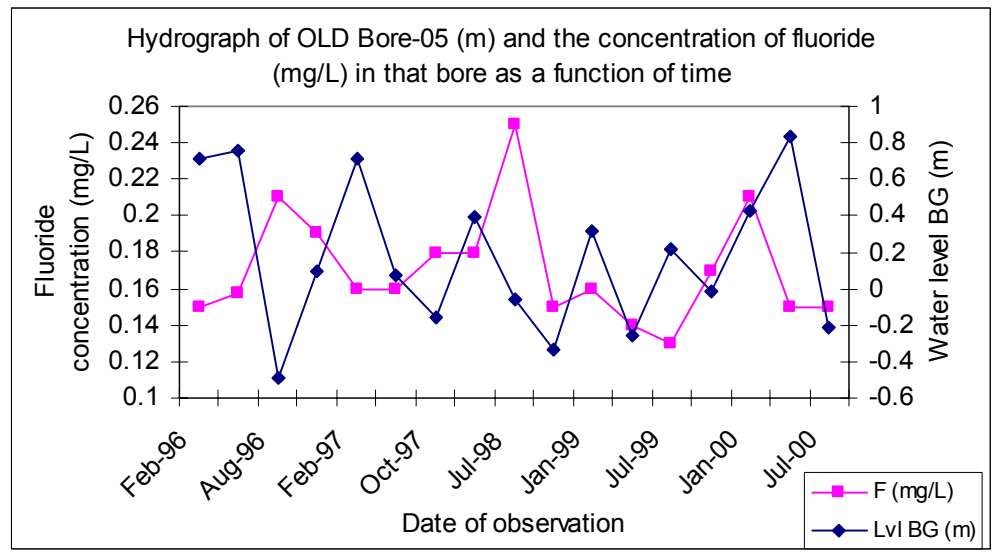

Figure 4: Hydrograph of OLD Bore-05 (m) and the concentration of fluoride $(\mathrm{mg} / \mathrm{L})$ in that bore as a function of time.

\subsection{Fluoride adsorption/desorption by flushing}

Fluoride is both highly soluble and highly mobile in the Portland smelter environment, as highlighted by fig. 4 and 5. It appears that fluoride is not simply bound up and locked away as an adsorbent or complex, it is not static and increasing in concentration as a function of continual deposition, but rather appears to be highly soluble and is moving rapidly in this highly hydraulically conductive environment. To assess this hypothesis, the fluoride adsorption capacity of the surficial sands and underlying clays was calculated for all collected aquifer media, table 1 . There was, not unexpectedly, significant heterogeneity in adsorption between all media tested, and as might be expected, all the clays have a much higher adsorption capacity that the sands. For instance, the reddish clay from New Bore 17, and the grey clay from beneath the blue gum plantation have a theoretical fluoride adsorption capacity of more than 450 $\mathrm{g} /$ tonne. The surficial sands, on the other hand, are much less adsorptive (range 37-209 g/tonne). The data also suggests that the adsorptive potentials of the aquifer media are far from being realised. One consequence of this finding is that it is highly unlikely that there is any significant vertical migration of fluoride 
through the clays underlying the Portland smelter site to the deeper drinking water aquifers. Another is that fluoride will not be readily adsorbed to the sands of the surficial aquifer and, indeed, that an influx of freshwater will allow desorption from the surface of the sands.

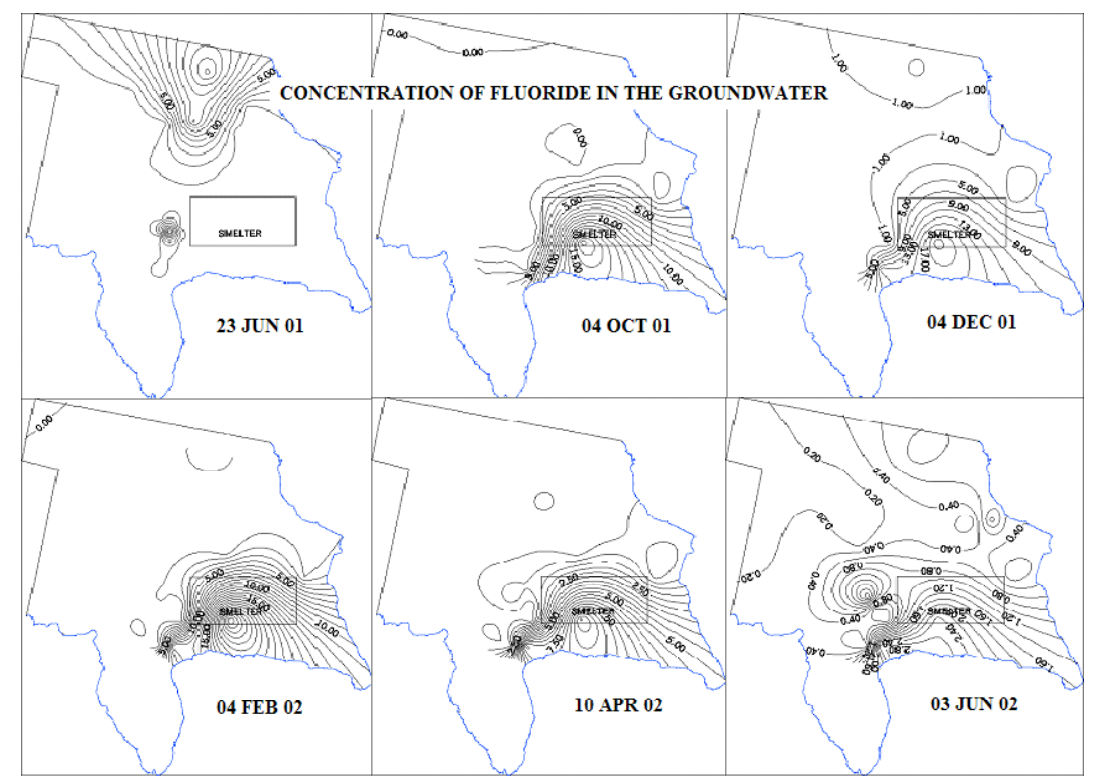

Figure 5: Contour maps of the concentration of fluoride $(\mathrm{mg} / \mathrm{L})$ in the groundwater during each sampling trip.

Table 1: Adsorption potential of the various aquifer mediums encountered. (L: Langmuir, F: Freundlich).

\begin{tabular}{|l|c|c|c|}
\hline \multicolumn{1}{|c|}{ Sample location } & $\begin{array}{c}\text { Coefficient of } \\
\text { determination }\end{array}$ & $\begin{array}{c}\text { Isotherm } \\
\text { rate of } \\
\text { change }\end{array}$ & $\begin{array}{c}\text { Estimated g F } \\
\text { adsorbed per tonne } \\
\text { of aquifer medium }\end{array}$ \\
\hline Cameron Hill Clay Pond Lining L & 0.97 & 17390 & 57.50 \\
\hline RED CLAY Aquifer material L & 0.97 & 2350.8 & 425.39 \\
\hline SAND NBORE-07 L & 0.92 & 10967 & 91.18 \\
\hline SAND NBORE-10 L & 0.92 & 26873 & 37.21 \\
\hline SAND NBORE-19 L & 0.92 & 4780 & 209.21 \\
\hline GREY CLAY L & 0.80 & 2200.6 & 454.42 \\
\hline SANDY CLAY NBORE-04 L & 0.96 & 3681.4 & 271.64 \\
\hline SAND NBORE-08 L & 0.94 & 8610.2 & 116.14 \\
\hline SAND NBORE-02 F & 0.23 & 6132.1 & 163.08 \\
\hline REDDISH CLAY NBORE-17 L & 0.77 & 2176.2 & 459.52 \\
\hline
\end{tabular}


To further investigate the hypothesis that under normal climatic conditions, winter rainfall will flush the fluoride from the surficial aquifers, desorption of fluoride from the surficial sands was investigated in more detail using data from the repacked core experiment. After collecting the water leaching through the columns, and determining the fluoride concentration therein, an exponential decay model was fitted to the plots of fluoride concentration against the total volume of water flushed (L) for the experiment duration (hours), e.g. fig. $6\left(\mathrm{R}^{2}>\right.$ 0.90 all models). When the fluoride recovered from the equilibrium solution was added to that in the leachate, more than $98 \%$ of applied fluoride was recovered, table 2 .

Table 2: $\quad$ Summary of leaching data.

\begin{tabular}{|c|c|c|c|c|c|}
\hline Unit & $\begin{array}{c}\text { Initial } \\
\text { volume of } \\
\text { water } \\
\text { recovered }\end{array}$ & {$[\mathrm{F}-]$} & $\begin{array}{c}\text { F- recovered } \\
\text { in } \\
\text { subsequent } \\
\text { drainage }\end{array}$ & \multicolumn{2}{|c|}{$\begin{array}{c}\text { F- retained on } \\
\text { column }\end{array}$} \\
\hline & $(\mathrm{mL})$ & $(\mathrm{m} / \mathrm{L})$ & $(\mathrm{mg})$ & $(\mathrm{mg})$ & $(\%)$ \\
\hline 1 & 775 & 4.46 & 5.42 & 0.13 & 1.3 \\
\hline 2 & 790 & 4.58 & 5.15 & 0.27 & 2.7 \\
\hline 3 & 685 & 3.81 & 6.06 & 0.13 & 1.3 \\
\hline Mean & 750 & 4.28 & 5.54 & 0.18 & 1.8 \\
\hline
\end{tabular}

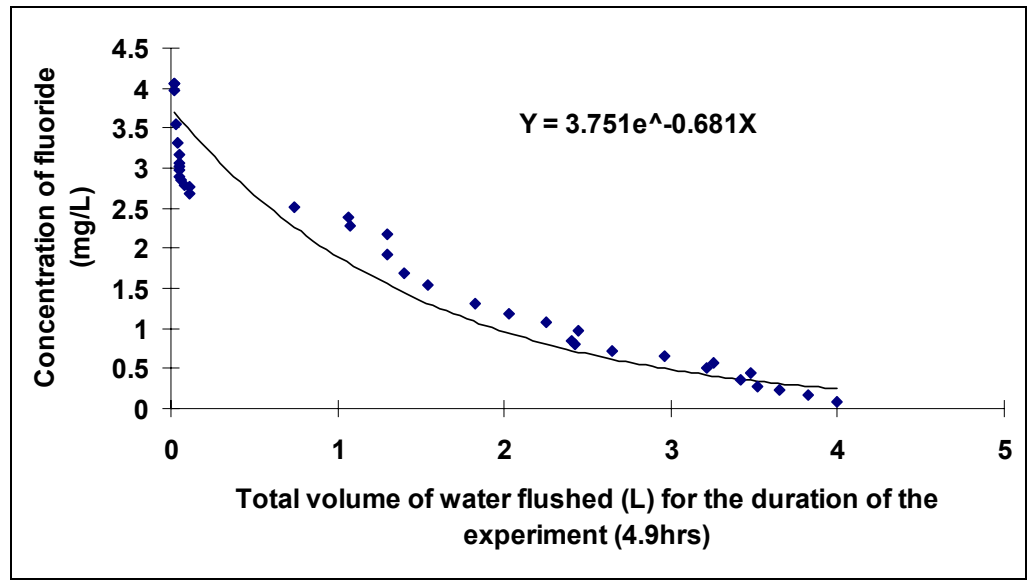

Figure 6: The concentration of fluoride $(\mathrm{mg} / \mathrm{L})$ as a function of the total volume of water flushed (L), for the duration of the experiment (hours).

The sands of the surficial aquifer contain a small amount of fine grained particles, possibly a clay fraction, which might account for the small amount of fluoride retained in the leachate experiment. Given that the adsorptive potential of the sands was estimated to have an average of $148 \pm 85 \mathrm{~g} /$ tonne, clearly some 
sands show reasonable adsorptive potential, with other sands quite possibly having almost no potential at all. However, any adsorptive potential is only realised when the concentration of fluoride is elevated in the waters of aquifer. When the concentration drops, such as when rainfall recharges the surficial aquifer, the equilibrium shifts and fluoride is freely desorbed. This is consistent with there being no long term build up of fluoride in the soils or groundwater. This finding at the Portland site is not the same as in studies of other sites. For example $[18,19]$ showed that some sands, not dissimilar to those underlying the Portland site, retain a very high adsorptive potential. Murray [19] suggested that $98 \%$ of fluoride was retained by highly leached, disturbed, fine grain sands $(0.1$ to $0.2 \mathrm{~mm}$ ) when exposed to low, intermediate, and high fluoride doses 10 years after the sand was disturbed by mineral sand mining. Murray [18] also investigated fluoride retention in sand podzols, and found that between 94.9 and $98.4 \%$ of fluoride was retained [18].

\subsection{Groundwater flow and contaminant modelling}

To evaluate the impact of various discharge regimes, a groundwater flow model of the whole site was constructed using MODFLOW. The model for groundwater flow was divided into two horizontal layers of stratigraphical uniqueness in accordance with established geomorphological evidence. All hydro-mechanical interpretations of geophysical findings were based on rigorous laboratory and field analysis conducted over three years. The model was calibrated using parameters that were consistent with field measured observations. Using seasonal averages, multiple distinct hydrological conditions were calibrated using the same parameter sets and boundary conditions. To ensure that the model utilised reasonable hydraulic estimates, sensitivity analysis was conducted during the calibration process. The model included a variety of sources of fluoride contamination, both diffuse, semi diffuse and point.

Given the marked potential adsorption differences within and between the sands and the clays in the surficial aquifers, it is not practical to model the three dimensional spatial distribution of fluoride concentrations in the groundwater solely based on the ability of aquifer media to adsorb this ion at one or more locations. Instead, where two different zones of transmissivity are included (adjacent to each other) into the domain that differs by one order of magnitude or more, an interpolative approach was taken.

Several intrinsic site factors directed the study towards a model that incorporated the hydrogeological averages of parameter assessment. These include the large irrigation volumes used on separate areas of the site at different times of the year (recharge can be rapid, and highly localised), the high hydraulic conductivity estimates for much of the surficial aquifer, the large amounts of anthropogenic soils found on site, the large areas of hard pan catchment, the many man made and natural wetlands, the many surface drains that crisscross the site, the large waste water storage facilities (some of which leak), and the continual input of fluoride from a variety of sources both point and diffuse. In such a heterogeneous environment where data is limited, professional judgement was used with a conservative approach. Thus an appropriate representation of the 
site was one that included enough detail to accurately estimate the annual averages, with a model described as the hydrogeologic average transport model the final output.

\subsubsection{The farmland transport model}

The farmland transport model (irrigation of pasture towards the north of the site) suggests that even though fluoride begins to migrate in a westerly direction almost immediately, after ten years the estimated contaminant plume is still retained within the Smelter's lands. Dose volume plays a vital role in hydraulic head variation in the model. Shortening the modelled disposal locations relevant position to the north and western model boundaries also decreases the time it takes for the contaminant to diffusely migrate across these boundaries. At terrestrial locations close to the model's boundaries, the topography of the site is relatively even at level 36-37 m. Mechanical dispersion by advection also favours a west and north-westerly migration of contaminant when $300 \mathrm{~kL}$ is dosed in small areas. However, the extremely high adsorptive nature of the clays of layer two, make it highly desirable to expose the smelters combined stormwastewater $\left(\sim 12 \mathrm{mg} / \mathrm{L} \mathrm{F}^{-}\right)$to this feature for as long a time as possible. The farmland transport model incorporates this trade off.

\subsubsection{Blue Gum Plantation and Terraced Wetlands transport models}

The Terraced Wetlands and the Blue Gum Plantation transport models suggest that fluoride cannot exit the model domain to the north or west of the site for the period modelled (40 years), but rather will discharge through Duttons and Grants Creek respectively. This is consistent with the piezometric contours that indicate that the flow direction is always from the west to the east. The large Peclet numbers estimated indicate that mechanical dispersion of the contaminant by advection dominates in the transport of the contaminant over diffusive flux or a diffusion gradient.

\subsubsection{Models of discharge to the north}

The above models indicate that if disposal is located near the boundary of the model domain particular challenges present. For example, the farmland transport model indicates that at some time ( $>40$ years), the contaminant will exit the site to the north and west. This is a function of the diffusive flux and an altered hydraulic head, which will affect the groundwater gradient thus altering flow direction. Therefore, if disposal of trade waste water is undertaken on the north of the site, it is desirable to ensure that this occurs at a distance of no less than $800 \mathrm{~m}$ from the defined catchment boundaries. This will ensure that the contaminated water is exposed to the clays of strata 2 for the greatest amount of time, and that the contaminant plume will migrate towards the eastern seaward boundary.

Irrigation of wastewater anywhere but to the north of the site will result in a contaminant plume that will ultimately discharge to the seaward boundary. If one accepts that it is unacceptable to directly or indirectly dispose of high fluoride waters to the surficial aquifer, and thus surreptitiously discharge this material into the ocean, what can be done with the waters? One option is to evaporate the 
water. Clays found on-site are an excellent candidate for use in the construction of a storage facility liner. To assess evaporation as a means of removing the waste water to achieve zero off site discharge a simple evaporation model was applied. For the Portland area, an annual mean evaporation is reported to be 1300 $\mathrm{mm}$ from open water bodies [20]. This equates to approximately $3.5 \mathrm{~mm} / \mathrm{day}$, and is consistent with [16], who reported localised evaporation to be 2-4 $\mathrm{mm} /$ day. The lower estimates are considered to be a function of the humidity associated with the large expanses of the nearby Southern Ocean. So as a best case scenario, the conservative estimate of $2 \mathrm{~mm} /$ day has been used. If $300 \mathrm{~kL}$ are required to be evaporated each day, from an area with an evaporative potential of at least $2 \mathrm{~mm} /$ day, then the required water surface area should be at least $150,000 \mathrm{~m}^{2}$, a body of water that could have no input from precipitation (600 to $800 \mathrm{~mm}$ per year).

\section{Conclusions}

There are several key factors that combine to make the Portland Aluminium smelter site unique when considering fluoride retention, migration and management. First, the site is and of itself a small catchment, made up of a large number of smaller catchments, restricting the ability of the contaminant to move off-site horizontally. Second, there is no interaction with deeper aquifers as there is an aquiclude, underlying the clay strata (a thick basalt layer 30-45 m deep), restricting the movement of the contaminant vertically. Thirdly, the sandy soils of the smelter site appear to have a very limited adsorptive potential, releasing the ion when rainfall is high, restricting the longevity of the contaminant in the system.

The main source of contamination to the terrestrial flora and fauna communities continues to be the smelter's airborne emission, with a likely northern contributor. Most drainage-water, runoff and groundwater, appears to exit the site to the marine environment via two points, specifically Grants and Dutton's creeks. Currently new technologies are being sought to reduce the amount of fluoride exuded as an airborne contaminant although the mass remains high. In light of the continual deposition of fluoride as an airborne contaminant and the persistent existence of the plants found on site, in conjunction with the observed surreptitious nature of fluoride migration off site, perhaps the company mandate of zero off site discharge may well require greater consideration.

\section{Acknowledgements}

We thank the Australian Research Council (ARC) Strategic Partnership with Industry Research Training (SPIRT) (Project \# C00002301) and Portland Aluminium for their financial support. This research was also, in part, supported by the Department of Primary Industries (Project \# 08271). A special thanks to the numerous staff of Portland Aluminium who assisted, including a sincere thanks to Mr Ron Jeffries, whose on-site technical advice and local knowledge was invaluable. 


\section{References}

[1] Supharungsun, S., Wainwright, M., Determination, distribution, and adsorption of fluoride in atmospheric-polluted Soils. Bulletin of Environmental Contamination and Toxicology 28, pp. 632-636, 1982.

[2] Rand, W.E., Schmidt, H.J., The Effect Upon Cattle of Arizona Waters of High Fluoride Content. American Journal of Veterinary Research 13, pp. 50-61, 1952.

[3] Weinstein, L.H., McCune, D.C., Field surveys, vegetation sampling, and air and vegetation monitoring. In: J.S. Jacobson \& A. C. Hill. Ed. Recognition of air pollution injury to vegetation: A pictorial atlas. Information Report 1, TR-7 Agricultural Committee. Pittsburgh, Air Pollution Control Association, pp G1-G4, 1970.

[4] Brewer, R.F., Sutherland, F.H., Guillemet, F.B., Effects of various fluoride sources on citrus growth and fruit production. Environmental Science \& Technology 3, pp. 378-381, 1969.

[5] Brewer, R.F., Sutherland, F.H., Guillemet, F.B., Sorption of fluorine by citrus foliage from equivalent solution of HF, NaF, NH4F and H2SiF6. Proceedings of the American Society of Horticultural Science 7, pp. 215219, 1960.

[6] Facteau, T.J., Wang, S.Y., The effects of aqueous sprays of NH4F on early improved Alberta peaches. Hortscience 7, pp. 505-506, 1972.

[7] Perkins, D.F., Millar, R.O., Neep, P.E, Accumulation of airborne fluoride by lichens in the vicinity of an aluminium reduction plant. Environmental Pollution (Series A) 21, pp. 155-168, 1980.

[8] Gilbert, O.L., Environmental effects of airborne fluoride from aluminium smelting at Invergordon, Scotland (1971-1983). Environmental Pollution (Series B) 39, pp. 293-302, 1985.

[9] Haidouti, C., Fluoride distribution in soils in the vicinity of a point emission source in Greece. Geoderma 49, pp. 129-138, 1991.

[10] Vike, E., Air-pollutant dispersal patterns and vegetation damage in the vicinity of three aluminium smelters in Norway. The Science of the Total Environment 236, pp. 75-90, 1990.

[11] Carr, G.W., Beauglehole. ALCOA Portland Aluminium Smelter Terrestrial Flora. Kinhill Planners Pty Ltd. Portland Aluminium Environmental Risk Assessment, Working Paper Number 11, 1980.

[12] Davies, F., Notcutt, G., Fluoride pollution from an aluminium smelter in Romania. Land Contamination and Reclamation, 8, pp. 9-12, 2000.

[13] Gill, E., ACLOA Portland Aluminium Smelter, Geology and Geomorphology. Kinhill Planners Pty Ltd, Golder and Associates Pty Ltd. Source: Portland Aluminium Document Archive, 1980.

[14] Butler, J.J., Garnett E.J., Simple procedures for analysis of slug tests in formations of high hydraulic conductivity using spreadsheet and scientific graphics software. Kansas Geological Survey, Open-file Report 2000-40. Kansas Geological Survey's Well Tests for Site Characterization project. Online. http://www.krewg.org/Hydro/ Publications/OFR00_40/ index.html 
[15] Shaw, D.J., Colloid and Surface Chemistry. Fourth Edition. ButterworthHeinemann Ltd. Reed International. Sydney, 1992.

[16] Salzman, S., Allinson, G., Stagnitti, F., Coates, M. Hill, R., Performance of constructed evaporation ponds for disposal of smelter waster water: A case study at Portland Aluminium, Victoria, Australia. Water Research 35, pp. 2121-2128, 2001.

[17] Black, G.C., \& Associates Pty Ltd., Portland Aluminium Transfer Station Quarry Road, Portland. Groundwater Monitoring Wells, Report Number 95239R, 1988.

[18] Murray, F., Fluoride retention in sandy soils. Water, Air, Soil Pollution. 20, pp. 361-367, 1983.

[19] Murray, F., Fluoride retention in highly leached disturbed soils. Environmental Pollution (Series B) 7, pp. 83-95, 1984.

[20] Bureau of Meteorology, Commonwealth of Australia. http://www.bom. gov.au. Last accessed: August 2002. 